\title{
Rapid Continuous Ruthenium-Catalysed Transfer Hydrogenation of Aromatic Nitriles to Primary Amines
}

\author{
Ricardo Labes ${ }^{a}$ \\ Davir González-Calderón ${ }^{a}$ \\ Claudio Battilocchio ${ }^{a}$ \\ Carlos Mateos*b \\ Graham R. Cummingb \\ Oscar de Frutos ${ }^{b}$ \\ Juan A. Rincón ${ }^{b}$ \\ Steven V. Ley*a \\ Innovative Technology Centre, Department of Chemistry, \\ University of Cambridge, Lensfield Road, Cambridge, CB2 \\ 1EW, UK \\ svl1000@cam.ac.uk

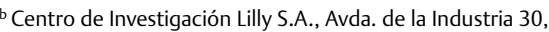 \\ Alcobendas-Madrid 28108, Spain \\ c.mateos@lilly.com \\ Dedicated to our friend Vic Snieckus on the occasion of his $80^{\text {th }}$ birthday
}

Received: 23.06.2017

Accepted after revision: 18.07.2017

Published online: 21.08 .2017

DOI: 10.1055/s-0036-1589096; Art ID: st-2017-r0508-I

License terms: (c)

Abstract A continuous flow method for the selective reduction of aromatic nitriles to the corresponding amine is reported. The method is based on a ruthenium-catalysed transfer-hydrogenation process, requires no additives, and uses isopropanol as both solvent and reducing agent. The process utilizes $1 \mathrm{~mol} \%$ of the commercially available [Ru(pcymene) $\left.\mathrm{Cl}_{2}\right]_{2}$, with a residence time of ca. $9 \mathrm{~min}$, and a throughput of $50 \mathrm{mmol} / \mathrm{h}$. The method was successfully applied to a range of aromatic nitriles providing the corresponding primary amines in good yields.

Key words nitrile reduction, transfer hydrogenation, ruthenium, primary amine, continuous flow

Amines are key intermediates in the production of fine chemicals, active pharmaceutical ingredients (APIs), agrochemicals, as well as many natural products. ${ }^{1}$ In particular, primary amines are important synthetic building blocks, as these are used in many processes such as the BuchwaldHartwig coupling reactions, ${ }^{2}$ hydroaminations, ${ }^{3}$ and alcohol amination by hydrogen-borrowing strategies ${ }^{4-7}$ for example.

The reduction of nitriles is among the most common route to generate the corresponding primary amines. ${ }^{8}$ The use of hydrides in stoichiometric amounts such as $\mathrm{LiAlH}_{4}$ is effective for this transformation, but catalytic hydrogenation methods using Raney Nickel, for example, are often preferred, however, these are not without problems. Despite being known for decades, ${ }^{9}$ transfer-hydrogenation processes $(\mathrm{TH})$ have gained in interest recently, ${ }^{10}$ also with applications to nitrile reduction. ${ }^{11-14}$ Transfer-hydrogenation techniques are attractive as they eliminate the need for

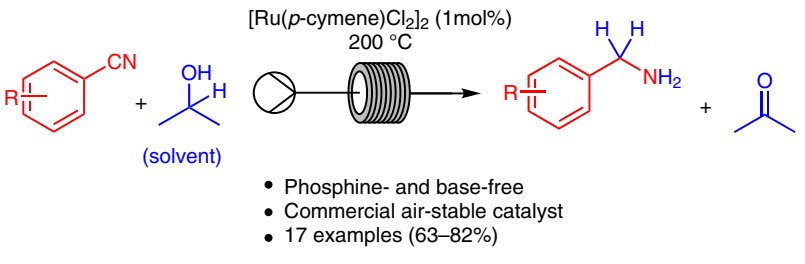

pressurized hydrogen gas typical of many catalytic methods. Both direct hydrogenation (employing $\mathrm{H}_{2}$ ), and $\mathrm{TH}$ methodologies can, however, suffer from selectivity issues and lead to several byproducts being formed in these reactions (Scheme 1). Several recent attempts have been reported to solve these selectivity problems employing catalysts and $\mathrm{H}_{2}$ gas $^{8}$ and selective TH reactions. ${ }^{11-13}$

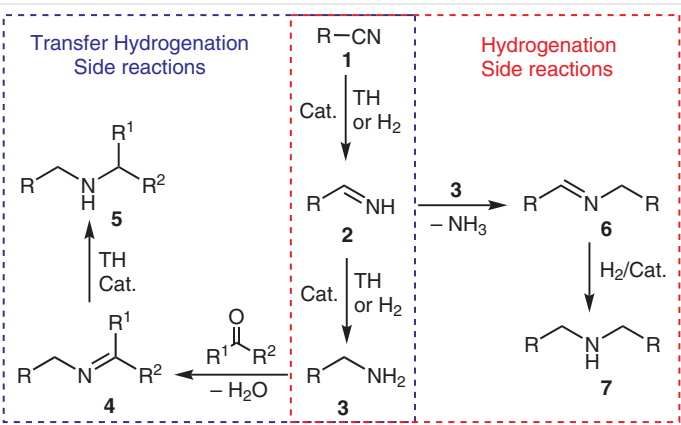

Scheme 1 Side reactions for the transfer hydrogenation and hydrogenation of nitriles

To the best of our knowledge, while hydrogenation reactions have been thoroughly investigated in continuous flow, ${ }^{15-20}$ including nitrile reductions to the correspondent primary amine ${ }^{21}$ and direct reductive amination, ${ }^{22}$ no continuous transfer hydrogenation of nitriles to primary amines has been reported so far. However, we could expect to see distinct advantages from the approach, especially in terms of safety and selectivity.

Beller and coworkers have reported the use of 2-butanol in the transfer hydrogenation of nitriles to obtain the corresponding primary amine while simultaneously reducing 
the formation of byproducts. ${ }^{11}$ The same group also reported a heterogeneous $\mathrm{TH}$ using $\mathrm{Pd} / \mathrm{C}$ and ammonium formate as a hydrogen source ${ }^{12}$ and the use of 2-propanol with $\mathrm{NaOH}$ to afford the alkylated secondary amines. ${ }^{23}$ On the other hand Zhou and Liu assessed two cobalt catalysts for $\mathrm{TH}$ of nitriles that led to the selective preparation of primary, secondary, or tertiary products. Here the solvent choice played a crucial role on the outcome of the reaction. ${ }^{13}$

Notably, three recent reports using transfer hydrogenation to reduce nitriles with a ruthenium catalyst led to the $\mathrm{N}$-isopropylidene derivatives (4, Scheme 1 ) as the main product through a further coupling and reduction. These studies use $\mathrm{KO}^{t} \mathrm{Bu}$ as base and relatively long reaction times. ${ }^{14,24,25}$ Recently, the use of a nickel catalyst and 1,4butanediol as hydrogen source to afford $N$-benzylidenes as main products of the transfer hydrogenation nitrile reduction have been observed. ${ }^{26}$

Even with all these advances, we felt there was a need for a practical, safe, and selective method for the transfer hydrogenation of nitriles, tolerant to a wide aromatic functionality. Inspired by our recent studies towards the chemoselective continuous ruthenium-catalysed hydrogen-transfer oxidation of secondary alcohols, ${ }^{27}$ we became interested in expanding the application scope of the system. Among other advantages of using a continuous-flow system is the precise control of residence times and heating regimes.

By analogy with our previous approach to continuous transfer hydrogenation, we devised a simple system comprising of a pump, a heated coil, and a backpressure regulator (BPR). Initial screening was performed using a Uniqsis FlowSyn ${ }^{28}$ unit equipped with a $20 \mathrm{~mL}$ stainless-steel coil reactor operating at the temperature indicated (Table 1).

Our study began employing triethylamine as a base, as it proved to be beneficial in our previous work employing the same catalyst. ${ }^{27}$ It was quickly realised that triethylamine was not in fact necessary for this transformation to proceed (Table 1).

Interestingly, Beller's report suggests that no conversion was observed using the same catalyst $\left[\mathrm{Ru}(p \text {-cymene }) \mathrm{Cl}_{2}\right]_{2}$ and 2-butanol at $120{ }^{\circ} \mathrm{C}$ for ten minutes in batch. ${ }^{11}$ We were pleasantly surprised to find that under the conditions described, even at $100{ }^{\circ} \mathrm{C}$ (Table 1 , entry 2 ), the expected primary amine could be observed in flow. By increasing the temperature to $150{ }^{\circ} \mathrm{C}$ the yield increased to $85 \%$ in the absence of phosphine ligands or base (Table 1 , entry 5). Concentration of the substrate in IPA was crucial to the outcome of the reaction. By increasing either the concentration of substrate or the amount of ruthenium catalyst, the amount of alkylated byproduct $\mathbf{5}$ increased. Residence time could be reduced to ten minutes maintaining the product yield. By reducing the residence time we diminished the amount of alkylated byproduct $\mathbf{5}$. However, we could now observe some unreacted imine $\mathbf{2}$, while the overall yield of primary amine was unchanged.
Table 1 Initial Optimisation for the Continuous TH of Nitriles

\begin{tabular}{|c|c|c|c|c|c|}
\hline & $\begin{array}{l}\mathrm{M} \text { in IPA } \\
\left.\text { ymene }) \mathrm{Cl}_{2}\right]_{2} \\
\mathrm{NEt}_{3}\end{array}$ & 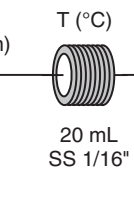 & & & \\
\hline Entry & $\begin{array}{l}\text { Residence time } \\
\text { (min) }\end{array}$ & $\begin{array}{l}\text { Temp } \\
\left({ }^{\circ} \mathrm{C}\right)\end{array}$ & $\begin{array}{l}\text { Cat. } \\
\text { (mol\%) }\end{array}$ & $\begin{array}{l}\mathrm{Et}_{3} \mathrm{~N} \\
\text { (equiv) }\end{array}$ & $\begin{array}{l}\text { Yield } \\
(\%)^{\mathrm{a}}\end{array}$ \\
\hline 1 & 40 & 100 & 0 & 2 & 0 \\
\hline 2 & 40 & 100 & 1 & 2 & 50 \\
\hline 3 & 40 & 125 & 1 & 2 & 75 \\
\hline 4 & 40 & 150 & 1 & 2 & 85 \\
\hline 5 & 40 & 150 & 1 & 0 & 85 \\
\hline $6^{\mathrm{b}}$ & 40 & 150 & 1 & 2 & 0 \\
\hline 7 & 40 & 150 & 0.5 & 0 & 80 \\
\hline 8 & 40 & 150 & 5 & 0 & 66 \\
\hline 9 & 20 & 150 & 1 & 0 & 85 \\
\hline 10 & 10 & 150 & 1 & 0 & 85 \\
\hline
\end{tabular}

a Yield of primary amine by ${ }^{1} \mathrm{H}$ NMR analysis (1,4-dinitrobenzene as internal standard) of the crude mixture after solvent removal.

${ }^{b}$ Using $\left(\mathrm{Ph}_{3} \mathrm{P}\right)_{3} \mathrm{RuCl}_{2}$ as catalyst.

The reaction system was then transferred to a Phoenix reactor platform, ${ }^{29}$ equipped with a $1 / 8$ " $35 \mathrm{~mL}$ stainless steel coil. This gave us the opportunity to work at even higher temperatures and pressures.

By precisely controlling the residence time of the solution we could halt the reaction at a specific equilibrium point between $\mathbf{1}$ and $\mathbf{5}$ (Scheme 1). The residence time was then optimized using benzonitrile as a model substrate. To enable a suitable downstream product isolation, we opted to isolate the primary amines as their hydrochloride salts, which could be easily separated by filtration, also enabling removal of any ruthenium residues. The general method was then applied to different nitriles (Table 2). ${ }^{30}$

Notably, aromatic nitriles bearing ether, thioether, chloride, and amide functionalities were all successfully reduced in good yields and good degree of selectivity. A pyridine derivative (Table 2, entry 16) was also converted into the desired primary amine in good yield. A nitrile compound containing an amide group (Table 2 , entry 15 ) selectively afforded the corresponding primary amine, however, substrates bearing more reactive carbonyl groups as in ketones or aldehydes led to a mixture of products.

Attempts to reduce aliphatic nitriles also led to poor yields due to reduced reactivity of these substrates. ${ }^{31}$ This expected lower reactivity has been observed by others. ${ }^{12,14}$ To further evaluate the robustness of the methodology, the system was operated continuously for two hours and afforded $4 \mathrm{~g}$ of benzylamine (Scheme 2 ). 
Table 2 Substrate Scope for the Continuous TH of Nitriles

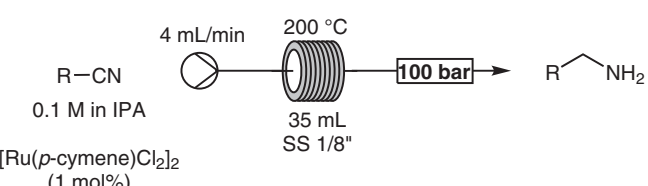

$(1 \mathrm{~mol} \%)$

\begin{tabular}{|c|c|c|}
\hline Entry & Substrate & Yield (\%) ${ }^{\mathrm{a}}$ \\
\hline 1 & & 78 \\
\hline 2 & & $71^{\mathrm{b}}$ \\
\hline 3 & & 80 \\
\hline 4 & & 69 \\
\hline 5 & & 76 \\
\hline 6 & & 71 \\
\hline 7 & & 69 \\
\hline 8 & & 70 \\
\hline 9 & & 72 \\
\hline 10 & & 82 \\
\hline 11 & & 70 \\
\hline 12 & & 78 \\
\hline 13 & & 72 \\
\hline 14 & & 63 \\
\hline
\end{tabular}

Table 2 (continued)

Entry Substrate

a Isolated yield as hydrochloride salts.

b Yield of primary amine by ${ }^{1} \mathrm{H}$ NMR analysis (1,4-dinitrobenzene as internal standard).

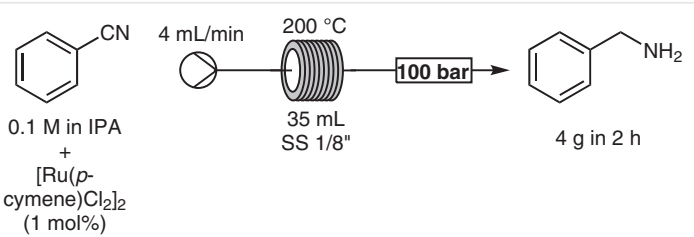

Scheme 2 Transfer hydrogenation of nitriles, 2 h continuous operation

To conclude, we have developed a fast, continuous, ruthenium-catalysed transfer hydrogenation of aromatic nitriles to afford primary amines. The system uses a commercial ruthenium catalyst and IPA as solvent and hydrogen donor. This system was successfully applied to reduce 17 different nitriles affording their correspondent primary amines in good yields.

\section{Funding Information}

This work was supported by Eli Lilly \& Co. through the Lilly Research Award Program (LRAP). This work has also been funded by the EPSRC (SVL, grants EP/K009494/1, EP/M004120/1 and EP/K039520/1).

\section{Supporting Information}

Supporting information for this article is available online at https://doi.org/10.1055/s-0036-1589096. Additional data is available from the University of Cambridge Data Repository website: https://doi.org/10.17863/CAM.10921.

\section{References and Notes}

(1) Hayes, K. S. Appl. Catal., A 2001, 221, 187.

(2) Ruiz-Castillo, P.; Buchwald, S. L. Chem. Rev. 2016, 116, 12564.

(3) Müller, T. E.; Hultzsch, K. C.; Yus, M.; Foubelo, F.; Tada, M. Chem. Rev. 2008, 108, 3795.

(4) Leonard, J.; Blacker, A. J.; Marsden, S. P.; Jones, M. F.; Mulholland, K. R.; Newton, R. Org. Process Res. Dev. 2015, 19, 1400 . 
(5) Bähn, S.; Imm, S.; Neubert, L.; Zhang, M.; Neumann, H.; Beller, M. ChemCatChem 2011, 3, 1853.

(6) Gunanathan, C.; Milstein, D. Angew. Chem. Int. Ed. 2008, 47, 8661.

(7) Imm, S.; Bähn, S.; Zhang, M.; Neubert, L.; Neumann, H.; Klasovsky, F.; Pfeffer, J.; Haas, T.; Beller, M. Angew. Chem. Int. Ed. 2011, 50, 7599.

(8) Bagal, D. B.; Bhanage, B. M. Adv. Synth. Catal. 2015, 357, 883.

(9) Brieger, G.; Nestrick, T. J. Chem. Rev. 1974, 74, 567.

(10) Wang, D.; Astruc, D. Chem. Rev. 2015, 115, 6621.

(11) Werkmeister, S.; Bornschein, C.; Junge, K.; Beller, M. Chem. A Eur. J. 2013, 19, 4437.

(12) Vilches-Herrera, M.; Werkmeister, S.; Junge, K.; Borner, A.; Beller, M. Catal. Sci. Technol. 2014, 4, 629.

(13) Shao, Z.; Fu, S.; Wei, M.; Zhou, S.; Liu, Q. Angew. Chem. Int. Ed. 2016, 55, 14653.

(14) Mai, V. H.; Nikonov, G. I. Organometallics 2016, 35, 943.

(15) Irfan, M.; Glasnov, T. N.; Kappe, C. O. ChemSusChem 2011, 4, 300.

(16) Cossar, P. J.; Hizartzidis, L.; Simone, M. I.; McCluskey, A.; Gordon, C. P. Org. Biomol. Chem. 2015, 13, 7119.

(17) Ouchi, T.; Mutton, R. J.; Rojas, V.; Fitzpatrick, D. E.; Cork, D. G.; Battilocchio, C.; Ley, S. V. ACS Sustain. Chem. Eng. 2016, 4, 1912.

(18) Ouchi, T.; Battilocchio, C.; Hawkins, J. M.; Ley, S. V. Org. Process Res. Dev. 2014, 18, 1560.

(19) Mennecke, K.; Cecilia, R.; Glasnov, T. N.; Gruhl, S.; Vogt, C.; Feldhoff, A.; Vargas, M. A. L.; Kappe, C. O.; Kunz, U.; Kirschning, A. Adv. Synth. Catal. 2008, 350, 717.

(20) Solodenko, W.; Wen, H.; Leue, S.; Stuhlmann, F.; SourkouniArgirusi, G.; Jas, G.; Schönfeld, H.; Kunz, U.; Kirschning, A. Eur. J. Org. Chem. 2004, 3601.

(21) Saito, Y.; Ishitani, H.; Ueno, M.; Kobayashi, S. ChemistryOpen 2017, 6, 211.
(22) Sharma, S. K.; Lynch, J.; Sobolewska, A. M.; Plucinski, P.; Watson, R. J.; Williams, J. M. J. Catal. Sci. Technol. 2013, 3, 85.

(23) Werkmeister, S.; Bornschein, C.; Junge, K.; Beller, M. Eur. J. Org. Chem. 2013, 2013, 3671.

(24) Paul, B.; Chakrabarti, K.; Kundu, S. Dalton Trans. 2016, 45, 11162.

(25) Lee, S.-H.; Nikonov, G. I. ChemCatChem 2015, 7, 107.

(26) Garduño, J. A.; García, J. J. ACS Omega 2017, 2, 2337.

(27) Labes, R.; Battilocchio, C.; Mateos, C.; Cumming, G. R.; de Frutos, O.; Rincón, J. A.; Binder, K.; Ley, S.V. Org. Process Res. Dev. 2017, DOI: 10.1021/acs.oprd.7b00190.

(28) Uniqsis FlowSyn http://www.uniqsis.com/paFlowSystem.aspx (accessed Jun 7, 2017).

(29) ThalesNano. Phoenix Reactor http://thalesnano.com/phoenixflow-reactor (accessed Jun 2, 2017).

(30) General Procedure

A solution $(50 \mathrm{~mL})$ containing the nitrile $(5 \mathrm{mmol})$, and dichloro( $p$-cymene)ruthenium(II) dimer $(0.05 \mathrm{mmol})$ in IPA (solution was sonicated until the catalyst was solubilized 10-50 min) was pumped at $4 \mathrm{~mL} / \mathrm{min}$ through the reactor coil heated at $200{ }^{\circ} \mathrm{C}$. The Phoenix backpressure regulator was set to manual at 30\%, which correlated to approximately 100 bar. A 10 $\mathrm{mL}$ fraction of the solution obtained from the system in steady state was used to prepare the hydrochloric salt. Yields are reported as isolated hydrochloride salts, unless otherwise stated.

\section{NMR Data for Entry 4}

${ }^{1} \mathrm{H}$ NMR $(600 \mathrm{MHz}, \mathrm{MeOD}): \delta=7.02-6.94(\mathrm{~m}, 2 \mathrm{H}), 6.90(\mathrm{~m}, 1$ $\mathrm{H}), 6.02(\mathrm{~s}, 2 \mathrm{H}), 4.13(\mathrm{~s}, 2 \mathrm{H}) .{ }^{13} \mathrm{C}$ NMR (151 MHz, MeOD): $\delta=$ $148.81,148.35,124.43,123.86,109.54,108.27,101.63,50.34$.

(31) Under the conditions in Table 1 , entry 5 cyclohexanecarbonitrile was not successfully converted into considerable amounts of the desired product. 